\title{
THE PROCESS OF INTRA-FIRM TECHNOLOGY TRANSFER: A CASE STUDY OF A MARINE MINING COMPANY
}

\author{
T. Behane ${ }^{1}$ \& S.S. Grobbelaar ${ }^{1,2 *}$
}

\section{ARTICLE INFO}

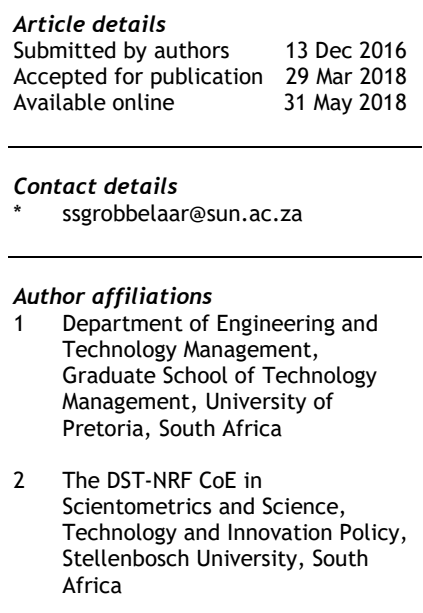

DOI

http://dx.doi.org/10.7166/29-1-1705
Technology transfer is an important function in the technology development cycle, and organisations can benefit extensively if a competent technology strategy is developed and implemented. The objective of this paper is to examine the approaches, processes, mechanism, barriers, and other aspects of intra-firm technology between two subsidiaries of a marine mining company. Subsidiary A of the marine mining company is primarily reliant on research and development as a key driver of technology development and continuous business improvement; an optimal technology transfer process is thus crucial. Using a case study methodology, the analysis sheds light on the current process to transfer technology, and major barriers to and elements of success.

\section{OPSOMMING}

Tegnologie-oordrag is ' $n$ belangrike funksie in die tegnologieontwikkeling siklus, en organisasies kan op groot skaal baat vind indien ' $n$ bevoegde tegnologie strategie ontwikkel en geïmplementeer word. Die doel van hierdie artikel is om die benaderings, prosesse, meganisme, hindernisse en ander aspekte van intra-firma tegnologie te ondersoek tussen twee filiale. Filiaal $A$ is hoofsaaklik afhanklik van navorsing en ontwikkeling as ' $n$ belangrike drywer van tegnologie-ontwikkeling en deurlopende besigheid verbetering; ' $n$ optimale oordrag van tegnologie proses is dus van kardinale belang. Met behulp van 'n gevallestudiemetodologie, werp die analise lig op die huidige proses om tegnologie oor te dra, en belangrike struikelblokke en elemente van sukses.

\section{INTRODUCTION}

Technological progress and innovation are widely accepted as being essential for driving the economic development of a nation, especially in developing countries [1]. Often having weak domestic abilities for technological development, developing countries usually depend on the absorption and assimilation of foreign technology [2]. In this respect, multinational corporations (MNCs) play a significant role in introducing and diffusing technology between and within firms, both nationally and internationally [3]. As MNCs expand into new markets, their success is in part determined by the ability to transfer competitive technologies to subsidiaries [4].

Matsuura and Yuhong [2] state that, in essence, two types of technology transfer (TT) involving MNCs can be identified. One is technology transfer from the parent firm to its overseas affiliates; and the other is technology transfer from overseas affiliates of MNCs to local firms. This research paper is focused on the first type of technology transfer, termed 'intra-firm technology transfer'. Although much has been written about TT between firms, public research establishments, universities, and industrial organisations, the literature on transfers that occur within multinational organisations remains sparse [5],[6]. This, however, is a topic of importance, as intra-firm TT has the potential to 
affect all levels of the value chain, including Research and Development (R\&D), production, and innovation management [7].

This research article presents a case study examining the process, barriers, and outcomes achieved through technology transfer between two subsidiaries of a marine mining enterprise. These are referred to from now on as Subsidiary A (situated in South Africa) and Subsidiary B (situated in Namibia). Using relevant literature and personal interviews, the study describes the transfer components of Subsidiary A, as well as specific aspects of the case studies selected for this research.

\section{LITERATURE REVIEW}

\subsection{Defining technology transfer}

For the purpose of this study, 'technology' is defined as a concept that is made up of two primary components: 1) a physical component that entails items such as tooling, products, equipment, processes, and techniques; and 2) the tacit component that comprises know-how in management, production, marketing, quality control, reliability, functional areas, and skilled labour [8]. For the purpose of the investigation, the concept of 'transfer' not only retains its defined meaning of moving something to another location, but also includes the use of the transferred item [9].

'Technology transfer' can be defined as a transfer of technical know-how, information, and people among corporate technical functions such as engineering, R\&D, and manufacturing, and nontechnical functions such as sales and marketing to yield innovative services and products that meet the strategic needs of a business and a customer [10],[4],[11],[5].

\subsection{Transfer overview and factors influencing technology transfer}

This section proposes a framework for the analysis of technology transfer and, through this framework, will attempt to highlight the barriers to technology transfer that are prevalent in an intra-firm business environment.

\subsubsection{The technology transfer process}

It is commonly mentioned in the literature that no two technology strategies are the same, and that therefore technology transfers need to be tailored to a specific context. To this end, Khabiri, Rast and Senin [12] provide a framework for the technology transfer process in the broadest sense. The process is defined as a sequence of four different stages: prospecting, developing, trial, and adoption.

Prospecting involves identifying the technologies that may be necessary to satisfy the needs of the end users. Developing involves further refining and enhancing the technologies. The trial stage involves the field testing of the technologies to ensure that they meet the performance criteria before being transferred to the end user. After success in the first three stages, the technology is further developed, if necessary, before it is implemented or adopted by the end user. This process is dynamic, and the stages may overlap or take place in parallel.

\subsubsection{Transfer strategies}

As with any complex system, developing a well-defined strategy can be the key factor for successful technology transfer. For the purpose of this article, a strategy is defined as a roadmap that outlines the progress of the task and identifies possible barriers [13].

Shama [14] reveals three types of technology transfer strategy that have been used by national R\&D facilities: passive, active, and entrepreneurial. Each strategy requires a certain level of commitment from the developer and the end user to make the strategy successful.

A passive strategy, or a response to a 'pull effect', is concerned with information dissemination, and entails providing information or responding to enquiries [14]. According to Jun and Ji [15], a pull strategy happens when end-users express their technological needs (and/or demands) first, and then try to source the technology. The manufacturer is made aware of the market need, a solution to address this need is sought and identified (source), and the innovation is transferred [16].

An active or 'push' strategy entails 'pushing' a technology into the marketplace [14]. Push transfer strategies start by identifying one or more innovations. Then the market/operator (destination) is made aware of the innovation, the associated market need, and the business opportunity, and the 
innovation is transferred (via some transfer mechanism) from source to destination [16]. The need for the technology may not exist at that moment, but the idea is to push the technology in anticipation of changing the paradigm in favour of the technology.

The entrepreneurial strategy integrates the passive and active strategies and introduces the idea of using the technologies to improve the economic wellbeing of an organisation, and thereafter to create jobs [14].

\subsubsection{Transfer elements}

The research conducted by Creighton, Jolly and Buches [17] revealed that there is a set of recurring elements that have been present in most successful technology transfer efforts. These can be either formal or informal, as shown in Table 1. Formal elements help to put together a framework that helps to facilitate the basic steps of the technology transfer process. The informal elements are intangible, yet play a major role in the technology transfer process. The elements are summarised in Table 1.

Table 1: Formal and informal technology transfer elements [17]

\begin{tabular}{|l|l|}
\hline \multicolumn{1}{|c|}{ Formal elements } & \multicolumn{1}{c|}{ Informal elements } \\
\hline Organisation to lead effort & Linking between source of technology and user \\
\hline Project established to identify technology transfer & Capacity to transmit and receive information \\
\hline Documentation of information & Credibility of parties involved \\
\hline Distribution of information & Willingness of parties to communicate ideas \\
\hline & Reward \\
\hline
\end{tabular}

\subsubsection{Technology transfer barriers}

The analysis of case studies within the literature has highlighted factors within multinational organisations that have a great influence on the technology transfer process. Gibson and Sung [18] determined four important variables for technology transfer processes within and between organisations. These are communication interactivity, geographical and cultural distance, technological equivocality, and personal motivation. Gibson and Sung [18] combine the four elements in what they describe as a technology grid that illustrates the importance of each factor in the success of a technology transfer process.

Core barriers that have been identified include communication, which can be improved through creating a favourable cultural environment, trust, stronger ties between units, and a shared vision [19],[20],[21]. Factors that also affect the ease with which knowledge can be transferred are a lack of absorptive capacity, lack of motivation, lack of retentive capacity in recipients, and arduous relationships [22]. Further issues may include company politics, portfolio strategy and business strategy misalignment, lack of appropriate technical and human resources, the lack of a demandside environment, infrastructure issues, and dispersed geographical locations [23],[24].

\subsection{In conclusion: An analytical framework}

From the literature review above, the framework for analysing the intra-firm technology transfer process can be summarised as illustrated in Figure 1. The analytical framework contains the core themes and driving factors used to analyse the study.

\section{RESEARCH METHODOLOGY}

Two case studies were selected, and information was gathered to describe the background of the technology, provide an overview of the transfer events, identify the transfer strategies, describe the transfer process used, and explore the elements and mechanism involved that are responsible for the success or failure of the transfer process.

The approach used was a combination of a case study and exploratory research. Primary data was collected through interviews with key individuals at Subsidiary A. This process consisted of interviews with the technology transfer facilitators assigned to manage each of the cases concerned with this research. The interview process was not limited to the interview questions; the session was used as an opportunity to understand other aspects of technology transfer that do not lie within the framework of this study (see Table 2). 


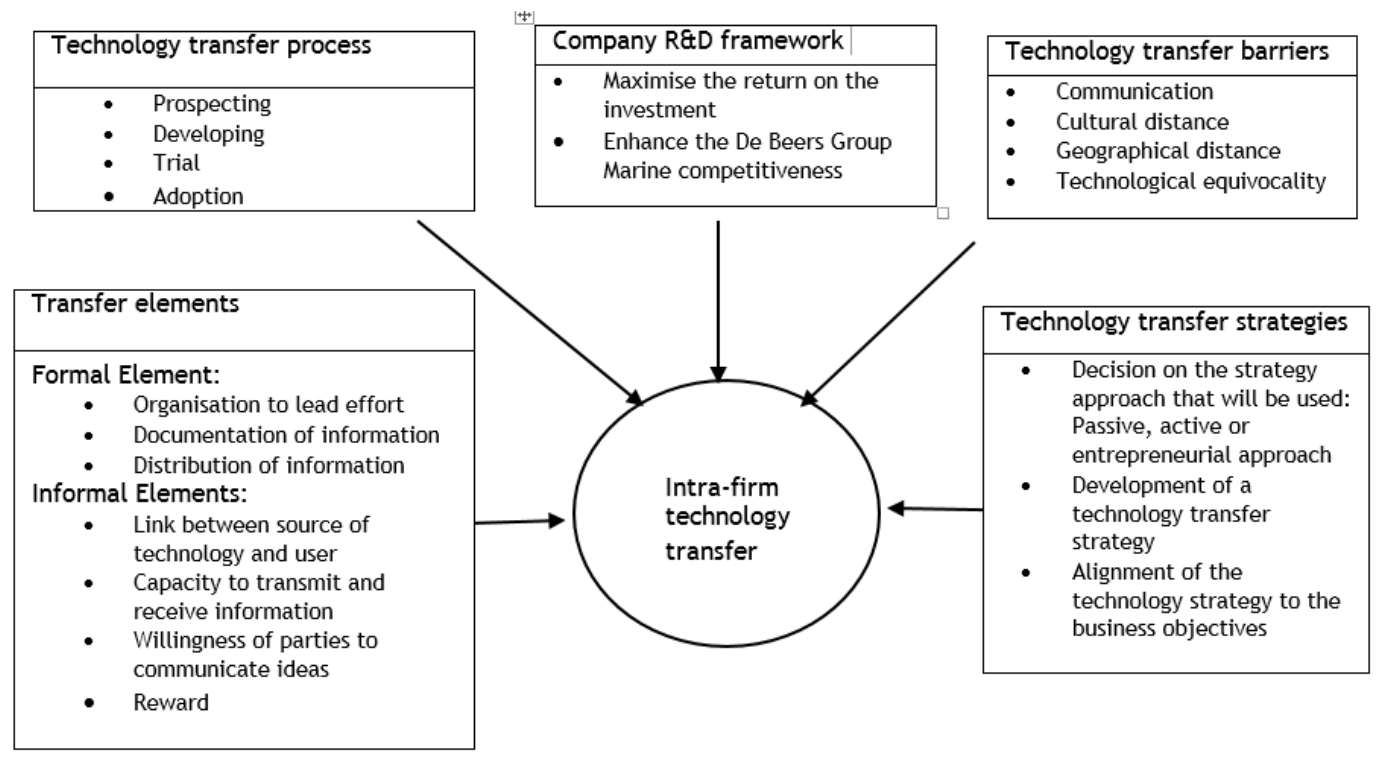

Figure 1: Technology transfer analysis framework

Table 2: Core areas of focus for the case studies

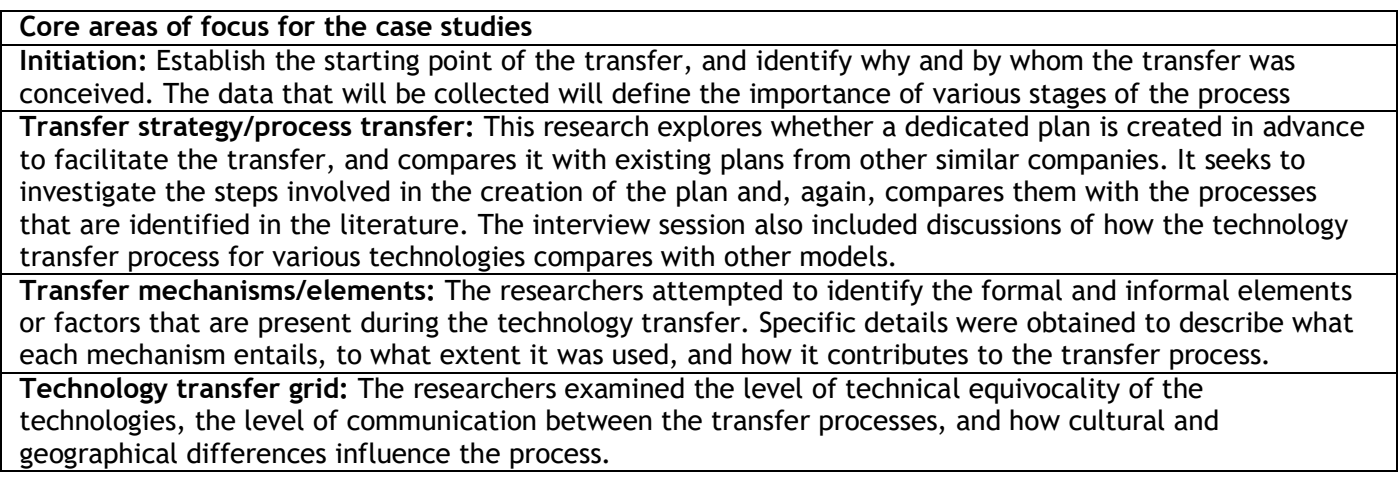

\section{RESULTS}

According to the Subsidiary A Research and Development Strategy Framework for 2015, the R\&D department at Subsidiary A has a strategic mandate to do the following: 1) maximise the return on the investment for the R\&D budget through the development of meaningful technologies and proactive technology transfer; 2 ) enhance the competitiveness of the company through rapid and direct transfer of Subsidiary A R\&D technologies to the market.

In addition, the department has a technology description document whose purpose is to identify all current and future technologies in a single source so that they may be reviewed by the end user. The technology description document describes the application of the technology - not only its intended purpose, but also how it contributes to the business objectives.

Subsidiary A needs to develop and transfer both soft (knowledge) and hard (tangible) technologies to Subsidiary B, which may include drawings, documents, and manufactured hardware. Although each technology is unique, the soft technologies at Subsidiary A tend to follow a similar process, and the same is true for the hard technologies. For this reason, two transfer cases of Subsidiary A will be analysed.

The first transfer case uses a single unit of analysis to illustrate the general process followed when transferring soft technologies. The second case uses multiple units of analysis to illustrate the process followed when transferring hard technologies. The cases examined are: 
1. Case study 1: The application of CFD to marine mining

2. Case study 2: Transfer of 'hard' technologies at Subsidiary A

\subsection{Case Study 1: The application of computational fluid dynamics to marine mining}

The design of marine equipment requires a detailed understanding of the water-flows that subsea technology will experience underwater during the mining process. This knowledge can generally be obtained through scale model testing at Subsidiary A's R\&D test facility. This type of modelling is limited, however, as it cannot accurately simulate complex water-flows that are reliant on hydrostatic pressure/water-depth pressure, due to the physical size of the test tank. As a result, computer programs such as computational fluid dynamics (CFD) are used to predict these flow characteristics that cannot be simulated at the test facility.

Complex mathematical equations are implemented in computer simulation models to analyse waterflow characteristics. The interaction of the water-flow, the seabed, and the marine equipment must all be considered. The CFD codes are validated by comparing data obtained from small-scale tests. Once the results have been validated for a specific application, they can be used to predict the performance of a design using realistic boundary conditions.

The development of CFD code is a significant technology in itself and requires the user to possess extensive knowledge and understanding of engineering fluid dynamics and computer programming. As part of a business requirement to improve the engineering designs and to reduce the development cycle of products, CFD was identified as an important strategic capability. In order to acquire this technology in the business, Subsidiary A was funded by Subsidiary B to purchase the CFD software from a computer software contractor for Subsidiary A.

Transfer overview. The project began with Subsidiary A, in collaboration with Subsidiary B, stating their engineering requirements to a software company. A decision to allow the software company to facilitate the transfer project according to Subsidiary A's standards was agreed on to facilitate a successful transfer.

The project was led by the software company, with the guidance of Subsidiary A, through the three stages: 1) verification of the feasibility of the application; 2 ) identification of the benefits of the application and verification of the existence of potential users within Subsidiary $A$; and 3 ) development of an after-sales support function to sustain the use of the technology.

Initiation of the transfer. Subsidiary A approached the software company after learning about the capabilities of CFD, and how it could answer some questions that small scale modelling simply cannot answer due to various limitations. Subsequently, preliminary high level discussions about requirements and capabilities were held, which included technical engineers and financial, procurement and technical management from both organisations.

The one barrier that was considered a threat was the lack of funding from Subsidiary B. Large mining firms, including Subsidiary B, are risk-averse, and they don't like investing in nascent technologies that are not proven to work reliably. They prefer to be 'technology laggards', and to adopt the technology when it reaches a certain level of readiness. Subsidiary B eventually funded the project because the rationale of using CFD to reduce the development cycle for future technologies made it a cost-effective solution.

Transfer strategy. The action of responding to enquiries is, by definition, a passive technology transfer. Subsidiary A employed a passive strategy, as the technology was introduced to the business by the software company. On gaining a wider perspective of Subsidiary A's working environment, the software company adopted an active transfer strategy by putting additional efforts in place that focused on pushing their technologies in areas where they saw the potential for this application.

It can therefore be concluded that the process was initiated mostly through a pull-factor, as it was Subsidiary A that realised a potential solution and subsequently made enquiries. However, as soon as the software company had obtained a wider perspective of marine diamond mining, and saw additional areas in which CFD could be applied, some technology push factors also came into play.

Transfer mechanism/elements. The interview showed that all of the informal and formal elements of Chen et al. [25] were present in this transfer case. One of the factors that made this transfer a 
success was the involvement of management at the preliminary stages of the transfer project. Furthermore, the distribution of information through briefings and informal meetings was noted as a key intervention in generating support for the project.

The linking of the developer's source of the technology with the end user was stressed as the most critical informal element in the success of the project. The end user was motivated by the idea of using software to simulate real-life scenarios and generate results, while the developer was motivated by the possibility of increased sales and the chance to enter a new market.

Given that it was the first time a CFD code had been developed for a marine diamond mining tool, research collaboration and technical assistance were crucial to the success of the transfer. The technology was handed over to Subsidiary A with a licence that had an expiry date and that required an additional fee for renewal.

Transfer barriers. CFD is a fairly mature technology. However, this novel implementation in the marine mining context means that its application remains untested, and much uncertainty could be associated with that.

The communication process was facilitated by the close proximity of the offices of Subsidiary A and the software company. This meant that formal and informal meetings were frequently held, thus improving the communication process. There was also a strong motivation to collaborate, as both parties benefited from this engagement: the software company was driven by an increase in sales and a new market to exploit, and Subsidiary A was motivated by a new technology with the potential to address many of their limitations. The element of equivocality can be said to be fairly low, because the transfer of technology, despite its complexity, is from one group of engineers to the next group of engineers.

Barriers that hindered this process were the complexity of the technology and the immaturity of its application in marine diamond mining tools. The capacity to absorb the technology was also recognised as a barrier because only a limited number of engineers at Subsidiary A had a good understanding of engineering fluid dynamics, which is essential for the operation of the technology.

\subsection{Case study 2: The transfer of 'hard' technologies at Subsidiary A}

This case focuses on how Subsidiary A, in general, facilitates the transfer of 'hard' technologies to Subsidiary B. The transfer conditions differ from one technology to the next; however, broadly speaking, most of the 'hard' technologies at Subsidiary A are transferred using a similar technology transfer process.

Given the unique nature of the underwater resource, and the large investment required commercially to exploit marine placer deposits, the marine mining firm's R\&D attempted to follow a decoupled technology development model in which technology and systems are developed and improved offline from the production systems. This requires extensive use of theoretical analysis and practical testing, typically on a scale model basis; while understanding the phenomena that control the behaviour of the systems and the interactions of the systems with the environment is very important. The decoupled model is not always possible, however, given the complexities of the real environment and the processes involved, and the limitations of theory and scale testing.

Many concepts are tested in a small-scale environment, and those that show potential for industrialisation are presented to the Subsidiary B stakeholders for full-scale trial testing. Once a proposal has been approved, manufacturing suppliers are contracted, and the R\&D engineer responsible for the project oversees the manufacturing phase, the technology transfer, and the implementation on board the vessel.

Considering the uniqueness of the environment in question, this case study aims to explore the strategies, processes, and challenges involved during the transfer of technology from Subsidiary A's R\&D department to Subsidiary B's plant operations.

Transfer overview. The transfer projects generally start with meetings involving high-level management to discuss the viability of the projects from financial, technical, and human resource points of view. On realising the feasibility of the projects at a high level, the projects are handed over to capable R\&D engineers to manage from the development phase until the handover phase. 
Broadly speaking, the transfer approach for hard technologies is somewhat similar to that for soft technologies, such as the CFD code. All the stakeholders, including the suppliers, developers, and the end users, are involved in the projects from the early stages. The key difference is that hard technology tends to adopt an active transfer strategy rather than a passive strategy. The technology transfer strategies for hard technologies are more involved, and the technology transfer requirements are more demanding. The transfer process involves more than just handing over the technology; the necessary training, maintenance, operational procedures, and after-sales support are important interventions to complete the transfer process.

Initiation of the transfer. The R\&D department at Subsidiary A uses a centralised off-line R\&D strategy to initiate all its medium- and long-term strategies. It also has a mandate to adopt a passive strategy and support production when there are problems in the mining plant that require R\&D solutions. Medium- and long-term projects are mostly concerned with futuristic methods of mining, while short-term projects tend to seek quick wins without introducing major changes to the way things work.

The link between the source of the technology and the end user very early in the project was once again stressed as being a critical component of the technology strategy. The interviewees maintained that, if the end user is involved in the process from the development of the technology, the transfer of technology is likely to be easier. This is because the idea of shared ownership is motivational, and ensures a better alignment of the project objectives with all the stakeholders involved.

Technology strategy. Although the engineers viewed the development of a formal transfer plan as important for successful transfer, interviews revealed that this is not normally done. In the absence of any formal policies and guidelines, some projects did prove successful without such measures. These successes were attributed to the project team members' working experience and the tacit knowledge of the project managers.

Transfer elements/mechanisms. The interviews showed that all of the informal and formal elements of Chen et al. [25] were present in the discussion of how Subsidiary A's developers transfer technologies off-shore. The process has its own set of problems in relation to cultural and geographical distances, equivocality, and lack of motivation.

The willingness of the end users to communicate their ideas to the development of the technologies is believed to have been a positive contribution. The interview revealed that most end users were somewhat reluctant to communicate ideas in the early stages - mostly attributed to an initial lack of confidence or knowledge about the technical requirements and the benefits. However, it was reported that, in some projects, the lack of willingness somewhat reduces as the project gains momentum. Likewise, their reluctance to make the project a success reduces as soon as they realise that performance targets are linked to that specific project. Essentially, the end user's willingness increases if some kind of reward is guaranteed at the end.

The interviews revealed furthermore the dissatisfaction expressed by the end users when developers focus mostly on the development of technology at the expense of after-sales support (maintenance documents, drawings, etc.). The engineers interviewed concede that they have a tendency to focus more on the technical aspects of the technology, while ignoring the requirements to develop installation, operating, and maintenance manuals for the technologies. The developer's presence on-site during the commissioning phase was also highlighted as a key intervention in the success of the transfer.

Transfer barriers. Given the unique nature of the business of marine mining, the technological solutions involved are inherently complex due to the absence of mature and off-the-shelf solutions. As a result, newly-developed technological solutions are generally handed over to the end users at a lower technology readiness level. This is usually due to time constraints or a lack of the resources that are needed to industrialise the technologies fully. This, in turn, leads to the following challenges:

- $\quad$ System failure and excessive trouble-shooting at the implementation phase of the technology;

- $\quad$ Resistance from the end user to use the technology because it is not proven technology, and may affect the mining targets that are linked to their performance reviews; 
- $\quad$ Efforts required to remove the technology from the system if it fails; and

- $\quad$ Lack of maintenance tactics.

The interviews revealed that the communication between the developers and the end users was not optimal, and that this negatively influenced the transfer. In some cases, the communication was low at the beginning of the project and tended to improve with time. The slow communication at the start was believed to be influenced by personalities, hierarchical positions, culture, and politics.

The geographical distance between the firms was recognised as a significant barrier. The developers attempted to close that gap by frequent travelling to the Subsidiary B offices or to off-shore mining sites. However, that on its own was perceived as not good enough. In addition to the challenges caused by geographical distance, cultural distance is also recognised as a barrier, and the solutions required to address this barrier are not known to the developers.

\section{CONCLUSIONS AND RECOMMENDATIONS}

The analysis of the cases showed that, despite the absence of a formalised technology transfer strategy, the undocumented technology transfer strategies demonstrated here are consistent with the organisation's culture and business objectives. The recurring themes and similarities imply that the transfer cases generally support the prevalent approaches, mechanisms, and processes that have been described in the literature. summarises the key findings of the case study.

Supported by the literature survey, the results from the analysis of the case studies suggest that the following specific findings can generally be applied to intra-firm technology transfer processes.

\section{$\underline{\text { Transfer process: }}$}

- Establish a top-level organisational strategy for technology transfer, and use it to facilitate the planning of the transfer stages, and to establish a culture for technology transfer within an organisation;

- Because all technology transfer processes are unique, approach the process on a project-byproject level to ensure that objectives and timelines are appropriate to the unique requirements of the project.

\section{Technology strategy and transfer elements:}

- $\quad$ Put portfolio management processes in place to ensure an overarching strategic approach to selecting projects;

- Identify a single individual to manage the transfer project. The idea of having a single point of contact is good for communication management, and minimises the potential for misunderstanding;

- $\quad$ Engage with end users right from the start. This is important in ensuring that appropriate objectives are set and in developing shared ownership of the technology. This tends to ensure less resistance to change on the part of the recipients of the technology;

- Undertake aggressive outreach efforts that emphasise pushing a technology into a new application. Consistently conduct market analyses to identify new potential end users. Once potential users are made aware of the technology, pull-efforts may be facilitated to assist the transfer process. Transfer efforts should focus on demonstrating the technology in its new application;

- Make use of personnel with relevant academic backgrounds and experience that will enhance the transfer process;

- Do not underestimate the informal elements, which are critical to the success of a technology transfer. Effective communication is paramount to a successful transfer process. It also minimises the geographical distance barrier. Make use of visual telecommunication technologies as part of the solution to address the geographical barrier;

- $\quad$ Tie motivation for collaboration to performance targets and rewards. 
- $\quad$ Establish measures for success. In their absence, it cannot be established whether or not the project was a success;

- $\quad$ Reduce the level of complexity in a technology to improve the transfer process and the effectiveness of the technology;

- Consider how to overcome: barriers of communication, lack of shared vision, lack of absorptive capacity, lack of motivation, lack of retentive capacity in recipients, company politics, portfolio strategy and business strategy misalignment, lack of appropriate technical and human resources, lack of a demand-side environment, infrastructure issues, and dispersed geographical locations.

Table 3: Summary of the case studies

\begin{tabular}{|c|c|c|c|c|}
\hline Case study & Transfer process & Transfer strategy & Transfer elements & Transfer barriers \\
\hline \multirow[b]{2}{*}{$\begin{array}{l}\text { The } \\
\text { application of } \\
\text { CFD to } \\
\text { marine } \\
\text { mining }\end{array}$} & GOOD & FAIR & GOOD & GOOD \\
\hline & $\begin{array}{l}\text { - All four stages } \\
\text { of the process } \\
\text { were present } \\
\text { (prospecting, } \\
\text { developing, } \\
\text { trial stage, and } \\
\text { adopting). } \\
\text { Technology } \\
\text { scanning is } \\
\text { exercised; } \\
\text { hence the } \\
\text { identification of } \\
\text { CFD } \\
\text { capabilities. } \\
\text { The technology } \\
\text { pull effect } \\
\text { becomes } \\
\text { dominant as } \\
\text { soon as benefits } \\
\text { of the } \\
\text { technology are } \\
\text { realised. }\end{array}$ & $\begin{array}{l}\text { - Subsidiary A prefers } \\
\text { passive strategy for } \\
\text { technologies that } \\
\text { are not their core } \\
\text { business. } \\
\text { However no formal } \\
\text { or documented } \\
\text { transfer strategy } \\
\text { was involved. } \\
\text { As soon as benefits } \\
\text { were recognised, } \\
\text { entrepreneurial } \\
\text { strategy was } \\
\text { adopted. The scope } \\
\text { for the application } \\
\text { of CFD increased, } \\
\text { and thereafter } \\
\text { created additional } \\
\text { jobs. }\end{array}$ & 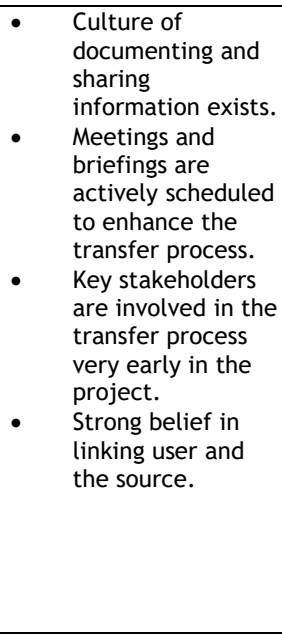 & $\begin{array}{l}\text { Complexity of } \\
\text { technology is } \\
\text { high, but the } \\
\text { engineers at } \\
\text { Subsidiary A are } \\
\text { capable of } \\
\text { absorbing and } \\
\text { diffusing the } \\
\text { technology. } \\
\text { Motivation is } \\
\text { high for use of } \\
\text { new technology/ } \\
\text { software by } \\
\text { engineers. }\end{array}$ \\
\hline \multirow[b]{2}{*}{$\begin{array}{c}\text { Transfer of } \\
\text { 'hard' } \\
\text { technologies } \\
\text { at Subsidiary } \\
\text { A }\end{array}$} & $\begin{array}{l}\text { ROOM for } \\
\text { improvement }\end{array}$ & ROOM for improvement & ROOM for improvement & FAIR \\
\hline & $\begin{array}{ll}- & \text { All four stages } \\
\text { of the process } \\
\text { are present. } \\
\text { Hard } \\
\text { technologies are } \\
\text { normally pushed } \\
\text { into operations. } \\
\text { New } \\
\text { technologies } \\
\text { receive } \\
\text { significant } \\
\text { resistance from } \\
\text { end users (plant } \\
\text { operators). } \\
\text { Engineers are } \\
\text { not involved in } \\
\text { the selection of } \\
\text { projects for the } \\
\text { R\&D portfolio. }\end{array}$ & $\begin{array}{ll}-\quad \text { No formal transfer } \\
\text { strategy involved. } \\
\text { Transfer strategy } \\
\text { depends on project } \\
\text { managers. } \\
\text { - } \quad \text { Lack of consistency } \\
\text { in technology } \\
\text { transfer strategies. } \\
\text { Successful transfer } \\
\text { projects happen } \\
\text { without formal } \\
\text { planning. } \\
\text { Importance of } \\
\text { technology transfer } \\
\text { is not sufficiently } \\
\text { appreciated by } \\
\text { engineers. }\end{array}$ & 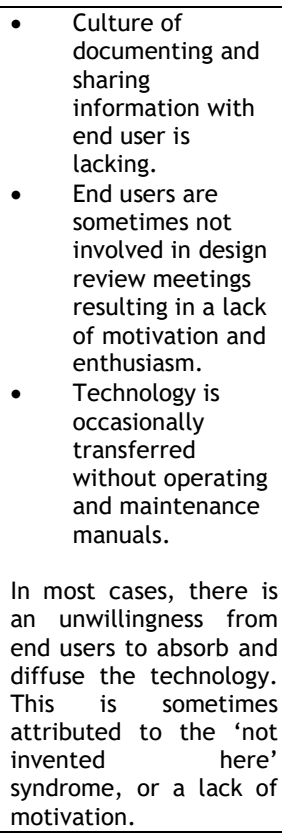 & 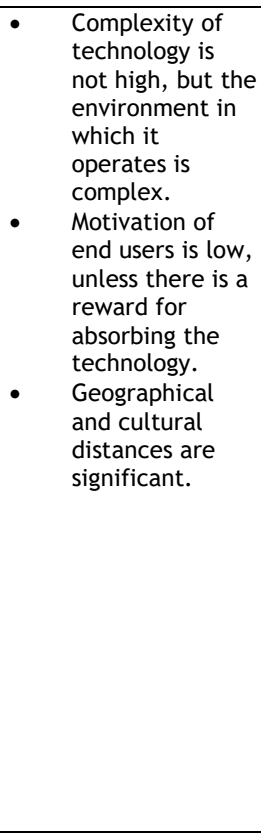 \\
\hline
\end{tabular}




\section{REFERENCES}

[1] Lee, J. and Win, H.N. 2004. Technology transfer between university research centers and industry in Singapore, Technovation, 24(5), pp. 433-442.

[2] Matsuura, T. and Yuhong, W. 2006. International intrafirm transfer of management technology, Economy, trade and industry, RIETI Discussion Paper Series 06-E-006, Waseda University.

[3] Zeile, W. 2014. Multinational enterprises and international technology transfer. Research Spotlight (September)

[4] Cui, A.S., Griffith, D.A., Cavusgil, S.T. and Dabic, M. 2006. The influence of market and cultural environmental factors on technology transfer between foreign MNCs and local subsidiaries: A Croatian illustration, Journal of World Business, 41(6), pp. 100-111.

[5] Chew, B. 2000. Technology transfer in Malaysian high technology industry, Institute Of Technology Management And Entrepreneurship, National Technical University, College Of Malaysia, p. 7.

[6] Zhelev, D. \& Mork, V. 2014. Intra-firm knowledge transfer: A qualitative case study of knowledge transfer and its implications in a soft service firm. Masters Thesis, Business Studies, Uppasala University.

[7] Malik, K. 2015. A conceptual framework for intra-company technology transfer: Cases of leveraging production process innovations across MNEs. Technology Analysis \& Strategic Management, 27:10, 11291142, DOI: 10.1080/09537325.2015.1060309

[8] Kumar, V., Kumar, U. and Persaud, A. 1999. Building technological capability through importing technology: The case of Indonesian manufacturing industry, The Journal of Technology Transfer, 24(1), 81-96.

[9] Le Grange, L. and Buys, A. 2002. A review of technology transfer mechanisms, South African Journal of Industrial Engineering, vol. 13, no. 1, pp. 81-100. [http://www.journals.co.za/ej/ejour_indeng.html

[10] Bozeman, B. 2000. Technology transfer and public policy: A review of research and theory, Research Policy, 29(4), pp. 627-655.

[11] Dhar, B.J.R. 2012, Foreign direct investment, intellectual property rights and technology transfer.Background paper No 6, UNCTAD

[12] Khabiri, N., Rast, S. and Senin, A.A. 2012. Identifying main influential elements in technology transfer process: A conceptual model, Procedia - Social and Behavioral Sciences, 40, pp. 417-423.

[13] Sun, Y. and Cao, C. 2015. Intra- and inter-regional research collaboration across organizational boundaries: Evolving patterns in China, Technological Forecasting and Social Change, 96(7), pp. 215-231.

[14] Shama, A. 1992. Guns to butter: Technology-transfer strategies in the national laboratories, The Journal of Technology Transfer, 17, p. 6.

[15] Jun, Y. and Ji, I. 2016. Demand-pull technology transfer and needs-articulation of users: A preliminary study, Procedia Computer Science, 91, pp. 287-295.

[16] Bauer, S. and Flagg, J. 2010. Technology transfer and technology transfer intermediaries, Assistive Technology Outcomes and Benefits 6, no. 1 (2010): 129-150.

[17] Creighton, J., Jolly, J. and Buckes, T. 1985. The manager's role in technology transfer, The Journal of Technology Transfer, 10, p. 16.

[18] Gibson, D. and Sung, T.K. 2005. Knowledge and technology transfer: Levels and key factors, International Journal of Technology Management, 29, p. 14.

[19] Inkpen, A. 2005. Knowledge acquisition and transfer in strategic alliances, in Knowledge management: Organizational and technological dimensions, J. Davis, E. Subrahmanian and A. Westerberg (eds), Heidelberg: Physica-Verlag HD, pp. 97-113.

[20] De Meyer, A. 1991. Tech talk: How managers are stimulating global R\&D communication, Sloan Managament Review, 49 (Spring), p. 7.

[21] Monica, L. 2013. Social capital and value creation: A replication of 'The role of intrafirm networks' by Wenpin Tsai and Sumantra Ghoshal, American Journal of Business and Management, 2, p. 8.

[22] Szulanski, G. 1996. Exploring internal stickiness: Impediments to the transfer of best practice within the firm, Strategic Management Journal, 17, p. 17.

[23] Boyle, K.A. 1986. Technology transfer between universities and the U.K. offshore industry, IEEE Transactions on Engineering Management 1 (1986): 33-42.

[24] Richardson, K. 2007. MNC and global R\&D. Report available: http://secure.com.sg/courses/ICl/Grab/Review_Questions/S07_Review_Answers.pdf

[25] Chen, J.K.C., Moslehpour, M., Lin, A.C.P. and Bayaraa, B. 2011. Exploring intra-firm technology transfer in the IC-industry: Case study of an international firm, in Technology Management in the Energy Smart World (PICMET), 2011 Proceedings of PICMET '11, pp. 1-9 